Article

\title{
The Barriers to Millennials Visiting Rouge Urban National Park
}

\author{
Gillian Ramsay, Rachel Dodds *, Daniela Furtado, Yana Mykhayletska, Anna Kirichenko and \\ Mana Majedian
}

Ted Rogers School of Hospitality and Tourism Management, Ryerson University, 350 Victoria Street, Toronto, ON M5B 2K3, Canada; g.ramsay48@googlemail.com (G.R.); daniela.furtado@ryerson.ca (D.F.); yana.pronin@gmail.com (Y.M.); akiriche@ryerson.ca (A.K.); mana.majedian@ryerson.ca (M.M.)

* Correspondence: r2dodds@ryerson.ca; Tel.: +1-416-979-5000 (ext. 7227)

Academic Editor: Tan Yigitcanlar

Received: 18 April 2017; Accepted: 24 May 2017; Published: 27 May 2017

\begin{abstract}
Intensified urbanization has led to more populated cities and less green spaces which are vital to community health, wellbeing and conservation. Rouge Urban National Park in Toronto has recently become Canada's first urban national park. This park is ideally suited to the millennial population, offering outdoor recreation and green space that this growing market generally desires. There is, however, a lack of research into visitor motivations to urban parks and more specifically millennial motivations. Findings from 280 quantitative surveys found three main barriers to visiting the Urban National Park: distance, transportation, and awareness. The lack of public transport combined with road congestion and fewer millennials owning cars creates issues with accessibility. Poor branding and knowledge through electronic media creates low awareness within a demographic market so tied to technology.
\end{abstract}

Keywords: urban national parks; millennials; distance decay theory; visitor motivations; Canada

\section{Introduction}

With general declines being seen worldwide in national park visitation and a $15 \%$ decrease seen within Canada alone in the past 10 years [1-3], it is important to look into why these numbers are declining and how to encourage different consumer markets to visit.

National parks are global phenomena and they are located globally across North America, Europe and Australia. In Canada, national parks are managed and maintained by Parks Canada, a department of the Government of Canada. The overall purpose of national parks is to protect and preserve the ecology, flora and fauna unique to a region as well as serve public recreational needs [4]. As defined by Parks Canada:

"National parks are established to protect and present outstanding representative examples of natural landscapes and natural phenomena that occur in Canada's 39 natural regions." [5]

Alternatively, urban national parks (UNPs), are defined as:

"... large parks within a city, serving the recreational needs of neighbouring residents" [6] (p. 1081).

The earliest UNPs were established in America in the 1970s and all are located within close proximity to large cities. These parks were created for two main reasons: residents' recreation and nature conservation [7]. With increased urbanization in recent years, much of the world's population live in cities, thus reducing available green spaces and access to parks [8]. The creation of UNPs aims to address this issue. In Canada, UNPs are maintained under Parks Canada with the first in Canada established in 2016 as Rouge Urban National Park (RUNP) in Toronto, Ontario. 
With overall declining visitations to national parks globally, millennial visitors can be considered a new market that could be key to helping increase those numbers. By encouraging younger people to connect with nature and learn about their environment, it is hoped that they will want to help preserve it. In that same way, by the millennial generation actively visiting UNPs, they can enjoy all the benefits of park usage as well as engage with nature and hopefully help preserve it. With an aging population and an ever-increasing demand on our natural environment, the need to engage a technology driven, young generation in conservation and nature is more important than ever.

Using the theoretical construct of distance decay, it could be considered that geographically "local" visitors be more likely to visit than those situated farther away. RUNP is the subject of this study as it is Canada's first UNP. This study aims to identify the main motivations and barrier for millennials visiting RUNP through analysis of millennial residents in the downtown core of Toronto, Ontario-Canada's biggest city. There has been much research into visitor motivations to national parks but few studies on millennial motivations and even fewer into urban parks, especially within Canada.

\subsection{Urban Parks, Urban National Parks and the Benefits of Visiting}

Urban parks are defined as "large parks within a city, serving the recreational needs of neighboring residents" [6] (p. 1081). Rouge Urban National Park is not the first urban national park, but it is the first in Canada. The first record of an UNP was established in the United States in the 1970s, with Rock Creek Park in Washington, DC, being frequently observed as the first [9].

Advantages to urban park visitation are plentiful and include better mental and physical health, opportunities for social interactions, crime reduction, environmental awareness, and conservation [3,10-14]. There is also a positive connection between green spaces in people's neighborhood and their physical and mental health status [10]. Urban residents who live within close proximity to a park report better health conditions as a result of physical activities associated with parks. This figure is of particular importance to Toronto's situation as studies have shown that up to $70 \%$ of Toronto's neighborhoods that suffer from high rates of diabetes lacked access to parks and recreation centers [12]. A well-planned and properly managed urban park can be considered an effective solution for preserving ecosystems, supporting biodiversity, and sustaining the environment [13], with parks like RNP supporting hundreds of plant and animal species [15].

Urban parks are "people parks" designed to be accessible and to serve the needs of the local community [12]. For these reasons, the demographics are different from national park users and vary from one urban park to another according to the demographics of the local community within which the park is located. Although a general profile of Toronto urban park users cannot be defined, previous studies have shown that urban park users typically live within five kilometers and visits are short, yet frequent, mainly to conduct exercise routines [8]. In saying this, the leading motivations to visit urban parks will vary between location depending on the design and layout, but the desire to appreciate nature is always paramount. Studies have indicated that language, level of education and gender are relatively weak predictors of park use but that age and proximity are greater predictors to urban park use $[8,16]$.

\subsection{Millennials}

The term "millennials" is often used in today's society and is defined differently dependent on different perspectives. To avoid any subjectivity for this study, the age group that the term "millennials" refers to is those born between the years 1981-1997, meaning those currently 18-34 years old [17]. This age group tends to be defined as the "digital generation", as this particular cohort is shaped heavily by the influences of technology- $75 \%$ of the millennial population being tech-savvy [18].

The millennial population in Toronto, Canada, is increasing. In Toronto, there are 2.5 million people living in the city and this number is steadily rising, with $45 \%$ of those being millennials [19]. Using 2011 census data, the city saw a 6.8\% increase in millennial residents between 2006 and 2011 that equated to over 38,000 extra individuals in only five years [19]. It is also evident that millennials 
have different travel motivations in comparison to other generations—one being enjoying nature [18]. For example, a travel experience for a millennial traveler is regarded as more than just a vacation; it is seen as a core value. According to a poll conducted in 2010, approximately 50\% of Canada's millennials regarded travel to be one of the most important aspects of their lives [17]. Millennial travelers typically look for new social and experiential travel activities, ultimately contributing to their personal growth. Additionally, millennial travelers tend to consider cultural exposure, authenticity, and the environment on their trips. Other motivational factors behind travel for millennials include the need to "show off", the need for individualism and personal expression, and the pursuit of novelty experiences. Based on the same survey results, popular activities undertaken during travel by millennials were eating and drinking local food, visiting popular tourist attractions, visiting cultural attractions, meeting local people, visiting family and friends (VFR), attending events and festivals, and, importantly, hiking. Due to this desire on behalf of this population segment, it is important to realize that there is a need to encourage this generation to visit natural areas in order to help protect them in the future [14]. This technologically driven millennial population, however, has been seen to limit their participation outdoors and if they are not engaged then they cannot help conserve and protect the environment $[3,20]$. Thus there is a paradoxical problem in trying to reach a technologically driven and socially connected population that desires nature, environmental and outdoor experiences. Add to this mix the ever-increasing costs of living in Toronto [21], decreased use of cars within the city [22], and the ability to travel for these experiences, visits to natural areas become much more difficult.

\subsection{Distance Decay}

Distance decay, also known as the friction of distance, is the theory that as distance to a destination increases, the likelihood and frequency of visitation decreases [23]. To travel a certain distance to somewhere is costly and even if the actual physical cost of travel to a location is not great, there are associated costs like uncertainty and time [24]. This can create distance decay effects as closer and better-known places are seen therefore as less costly. One study applied distance decay theory to visitors to a national park in China and found that older tourists will travel farther distances to visit compared to younger (millennial) visitors [25]. This study even went as far as to say that age was a motivating factor in how far consumers were willing to travel from in order to visit a national park [25]. In the case of this study into millennial motivations, this would then imply that younger people are in fact less likely to travel farther distances but older populations would. Another study tested distance-decay theory on Brisbane's D'Aguilar National Urban Park in Australia and findings revealed that peak visitation came from visitors five to ten kilometers away in order to specifically undertake experiences local neighborhood parks could not offer [8]. Significantly, this study also showed that millennials were in fact more likely to visit parks and green spaces located further distances from them than older populations [8]. Those with a high affinity to nature are more likely to travel further distances, visit more frequently and spend more time at parks opposed to those with a low affinity but are within a closer proximity $[16,26]$.

Distance effects are therefore inconsistent, one study showed millennials traveling shorter distances [25] and the other showed them travelling farther distances [8]. It could be said that with the latter being a study into UNP users and having been completed far more recently, it is therefore a more comparable study to this one. In that case, the suggestion should be that millennials are willing to travel from further away to visit RUNP, but it is clearly seen that this is not the case. Another study also used distance decay to study national park visitors in America and worked with the theory that parks farther away are seen as less congested and therefore more desirable creating almost an opposite case to distance decay theory [24]. This study also mentioned, however, that closer parks, which could be interpreted as UNP, provide necessary green areas for more frequent, short-term visits with fewer people visiting as distance increased away from these areas [24]. Finally, a key finding was that the more services and recreational opportunities a park offered, the further people would travel to visit [24]. 
Using these previous studies and with the knowledge that RUNP offers many services, it could be hypothesized that consumers are willing to travel farther to visit the park. However, with millennials being inclined to not travel to visit, the study presented here is targeting millennial respondents with the theory that despite being within the catchment of an urban national park, young people are not visiting RUNP. The key aim of this study, therefore, is to try and determine what the biggest barriers are to travelling to RUNP despite being within the urban catchment. It cannot be expected that every millennial will want to visit RUNP and so, to be more specific, this study is aiming to look at the barriers to millennials visiting RUNP that have an interest in green spaces, outdoors and nature. Distance is hypothesized as being the largest barrier to millennial consumers, which would therefore dispute the findings that millennials are willing to travel farther to visit UNPs [8] and creates the following hypotheses for this study:

Hypothesis 1. Millennials who have an interest in nature and the outdoors will be less inclined to visit RUNP despite their motivations.

Hypothesis 2. Distance to the park will be considered the largest barrier to millennial visitors to RUNP.

\section{Methods}

\subsection{Study Area}

Rouge Urban National Park (RUNP) was established in 1995 and became Canada's first national urban park in 2016 [27]. The park is located in the eastern Scarborough district of Toronto Canada and stretches from Rouge Beach at Lake Ontario all the way up to Oak Ridges Moraine. The park covers $40 \mathrm{~km}^{2}$ of surface and became $79.1 \mathrm{~km}^{2}$ in size when finally established [28], making RUNP one of the largest national urban parks in North America [29] and the world [30]. RNP has diverse physical landscapes that comprise of outcrops, glaciated landscapes, lakes and rivers, hoodoos and ravines [31]. It also hosts a rich biodiversity of more than 1700 plants and animals species [32]. The park is rich in human history with areas dating back to 10,000 years BC [33]. Finally, RNP offers visitors a range of activities including hiking trails, beaches, campgrounds, bike paths, bird watching, canoeing, swimming, geocaching and fishing [34].

\subsection{Survey}

A quantitative study of 360 people was carried out in spring 2016 and surveys were gathered both in person and online. Surveys were collected in Toronto, ON, as this is where RNP is located, with 210 gathered in person and 150 online. In person surveys were conducted both at Union Station and Yonge and Dundas Square in downtown Toronto, ON. These are both high-traffic areas in the downtown core of the city and were therefore considered the best location to gain a convenience sample of respondents. In total, 280 usable surveys were collected of respondents aged between 18 and 34, the age threshold for millennial classification used in this study. The loss of 80 surveys was due to respondent ages being out of these thresholds or data being incomplete. The survey consisted of three parts: (1) Rouge Urban National Park, (2) Canadian parks and (3) demographics. The first part aimed to assess the awareness of the park and its attributes and examine barriers to visiting the park within the next 12 months. The second component questions aimed to identify previous park behavior and motivations and the final section aimed to obtain general demographic information on marital status, household size, household income, age, race and ethnicity as well as postal code of residence. The survey was made up of 22 questions that were mostly closed-ended, with one being open-ended and another a Likert-scale question. The close-ended questions were structured with a fixed set of answers to choose from, however seven questions had an option of "other" to write open-ended and unstructured answers. 


\subsection{Data Analysis}

The collected survey data, from both in person and online questionnaires, was entered into SPSS to enable data processing, information management, and to ascertain specific and hidden relationships between different variables [35]. The data was pre-coded through a designing codebook and then cross-tabulated and organized into tables. This allowed findings to be categorized and analyzed more effectively. The survey data was assessed to prepare a profile of previous and prospective visitors, determine the motivations and barriers respondents have to visit Rouge National Urban Park and determine whether or not respondents are interested in shuttle bus services to and from the park. This was done using the frequency and cross-tabulation functions. There were no differences in responses between millennials questioned online versus in person. As both sampling techniques involved random sampling of all ages, one was not preferential to age of respondents over another and so all results were analyzed together rather than separately.

\section{Results}

\subsection{Profile of Respondents}

All respondents were aged 34 years or younger, with the youngest being 18, and the majority being under 24 years of age. A wide variety of race was recorded with the largest amount being Caucasian $(47 \%)$. As in line with this age group, the vast majority were single $(80 \%)$, and income on the lower end of the scale (see Table 1).

Table 1. Frequency table showing demographics of study sample.

\begin{tabular}{lc}
\hline Age $(\boldsymbol{n}=\mathbf{2 7 5 )}$ & (\%) \\
\hline 18 to 24 & 62.5 \\
25 to 34 & 35.7 \\
Race $(n=278)$ & \\
Caucasian & 46.4 \\
South Asian & 14.3 \\
Middle Eastern & 10.4 \\
East Asian & 9.6 \\
Latin or Hispanic & 4.3 \\
Caribbean & 3.6 \\
African & 2.5 \\
Other & 1.1 \\
North American Aboriginal & 0.4 \\
\hline Marital Status $(n=278)$ & \\
\hline Single & 80.4 \\
Married & 10.0 \\
Common law & 7.5 \\
Widowed & 0.7 \\
Separated & 0.4 \\
Divorced & 0.4 \\
\hline Income $(n=273)$ & \\
\hline Under $\$ 49,999$ & 38.6 \\
\$50,000 to $\$ 99,999$ & 34.3 \\
\$100,000 to $\$ 149,999$ & 16.1 \\
\$150,000 to $\$ 199,999$ & 5.7 \\
\$200,000 to $\$ 249,999$ & 0.7 \\
\hline
\end{tabular}




\subsection{Familiarity and Barriers to Visiting}

Respondents were first asked general familiarity questions about RUNP. A large majority (75\%) of respondents had never heard of the park and $90 \%$ had not visited within the last 12 months. Of those who had heard of RUNP (25\%), when asked on their familiarity with the attributes of RNP that appeal to millennials, $70 \%$ had not heard about the hiking trails in the area, $77 \%$ had not heard about RNUP camping, 70\% had not heard about picnic areas, $82 \%$ had not heard about the historical sites in the area, and 70\% were unaware of the natural landscapes, flora and fauna of RUNP (see Table 2).

Table 2. Frequency table showing respondent unfamiliarity with RUNP attributes.

\begin{tabular}{ll}
\hline \multicolumn{1}{c}{$(\boldsymbol{n = 2 8 0 )}$} & $\mathbf{( \% )}$ \\
\hline Skating & 83.6 \\
Historical Sites & 81.8 \\
Canoeing & 81.1 \\
Camping & 77.1 \\
Fishing & 76.4 \\
Swimming & 73.2 \\
Hiking & 71.1 \\
Nature and Scenery & 70.4 \\
Picnic Areas & 67.9 \\
\hline
\end{tabular}

The majority of millennials (57\%) would not be likely to visit RUNP in the next year while $34 \%$ said they would be somewhat likely. When questioned on all the reasons respondents would be unlikely to visit in the next year, 58\% considered it too far for them to travel to, 20\% replied that it was not easily accessible, 23\% considered lack of a personal vehicle an issue, and 20\% said they were lacking information about the urban park. To try and help pinpoint an exact barrier to RUNP usage by millennials, the survey asked for respondents to identify the biggest barrier of the options just previously given. Distance to the park was the biggest barrier, with $40 \%$ saying it was their largest barrier to visiting (see Table 3), followed by not interested (24\%). Almost 5\% cited other but did not elaborate.

Table 3. Frequency table showing the biggest barrier respondents felt was responsible to them visiting.

\begin{tabular}{lc}
\hline \multicolumn{1}{c}{$(\boldsymbol{n = 2 8 0 )}$} & Percentage (\%) \\
\hline It is too far. & 39.6 \\
Not interested. & 23.9 \\
Not easily accessible by public transportation. & 12.5 \\
Limited accessibility to more information. & 10.4 \\
Do not have easy access to a car. & 5.7 \\
Other & 4.6 \\
High transportation costs. & 3.2 \\
\hline
\end{tabular}

Seeing as distance and transport are two of the largest barriers, when asked about transportation to the park, of the $14 \%$ who had visiting RUNP in the last year, the majority came by car and second by public transit (see Table 4). Of those who had not visited, if they were to choose one form of transport to get to RUNP, $66 \%$ said personal car and $20 \%$ said public transit (see Table 5). This could partially be due to a lack of public transport links to RUNP. When asked specifically about using a shuttle bus from central Toronto, if it were to be offered, only a quarter said it would not be likely they would use it with the remainder saying it was likely. When pushed further and asked what price a consumer would be willing to pay to travel to RUNP by shuttle bus, the price outlined by the majority $(73 \%)$ was $\$ 3$ to $\$ 5$. 
Table 4. Frequency table showing how consumers travelled to RUNP in the previous 12 months.

\begin{tabular}{lc}
\hline \multicolumn{1}{c}{$(\boldsymbol{n = 2 8 0 )}$} & Percentage of All (\%) \\
\hline I have not visited in the past 12 months & 86.8 \\
Car & 8.2 \\
Public transportation & 2.9 \\
Bicycle & 0.7 \\
Walk & 0.7 \\
Uber & 0.4 \\
\hline
\end{tabular}

Table 5. Frequency table showing how consumers would travel to RUNP if there were to visit in the next 12 months.

\begin{tabular}{lc}
\hline \multicolumn{1}{c}{$(\boldsymbol{n = 2 6 8 )}$} & Percentage of All (\%) \\
\hline Car & 66.1 \\
Public transportation & 20.4 \\
Uber & 5.0 \\
Bicycle & 1.8 \\
Walk & 1.1 \\
Other & 1.1 \\
\hline
\end{tabular}

\subsection{Visitation to National Parks}

In addition to information about visiting RUNP, the survey gathered material on millennial visits to National Parks in Canada as well as urban parks in general. Despite $90 \%$ having not visiting RUNP in the previous 12 months and the $75 \%$ unfamiliarity rate, $73 \%$ of respondents have visited Canadian National Parks at least once in the last year and learned about them online (15\%), through word of mouth $(28 \%)$, or had them recommended $(40 \%)$. In regards to urban parks, $78 \%$ have visited one in the last year with the biggest motivations being to enjoy fresh air (61\%), enjoy nature (50\%), or spend time with family and friends (58\%) (see Table 6).

Table 6. Frequency table showing respondent motivations to visit urban parks.

\begin{tabular}{ll}
\hline \multicolumn{1}{c}{$(\boldsymbol{n = 2 8 0 )}$} & $\mathbf{( \% )}$ \\
\hline Outdoors and fresh air. & 61.8 \\
Time with friends and family. & 57.9 \\
Appreciate nature, animals and scenery. & 50.4 \\
Near workplace, home or study. & 36.1 \\
Something new. & 32.1 \\
Peace and quiet. & 28.2 \\
Attend an event. & 22.1 \\
Cycling. & 15.7 \\
Walk dog. & 10.0 \\
Visit historical sites. & 8.9 \\
\hline
\end{tabular}

\subsection{Cross-Tabulation and Chi-Squared}

In order to look deeper into reasons for non-visitation, chi-square tests were calculated to investigate any further patterns. This allowed the relationships between sets of variables to be analyzed with any results showing a significance value less than 0.05 having a $95 \%$ confidence level and any value between 0.1 and 0.05 implying a 90\% confidence level. Any significance value outside of 0.1 was considered not significant, as the confidence level was deemed too low to make any determinate statements about the relationship between those variables. To determine if the idea of distance decay was present and to determine how far millennials were willing to travel to RUNP, the biggest barrier to visiting was investigated against the likelihood of millennials visiting in the next year. What was 
found was that the barriers did affect people travelling to RUNP but within each individual barrier, there was no significance found between that particular barrier and a consumer's likelihood to visit RUNP. However, this is likely due to not all respondents being future consumers of RUNP. In order to investigate this idea further, it is presumed that all respondents who answered "they liked to be outdoors and enjoy fresh air" as visitor motivations, are potential consumers as their interests are more aligned to those of park visitors. The same can be considered for those who answered they "appreciated nature, animals and scenery" as motivations to visit UNPs. For the sake of this study these two motivational groups have been named OUTDOOR and NATURE, and both were used in analyzing and relationship between their respondent group and their biggest barriers to visiting RUNP.

As seen in Table 7, all respondents who answered that they liked to be outdoors (thus labeled OUTDOOR) had almost an equal split between being likely and not likely to visit RUNP. When looking at what the biggest barrier is to allowing these specific respondents to visit RUNP, a significant value ( $p=0.026$ ) (see Table 8 ) is seen with a 95\% confidence level, which implies that there may be some relation between these barriers affecting a respondent's likelihood to visit RUNP if they like the outdoors. The largest perceived barrier was that the park is considered too far away to travel to. When this single barrier of distance was analyzed for those who enjoy being outdoors, it can be seen from Table 9 that there is a significant relationship $(p=0.032)$ between these variables at a $95 \%$ confidence level, thus implying that RUNP being too far to visit may have some relationship with the lack of visitation from those who like being outdoors. As seen from Table 10, there is another significant relationship ( $p=0.006$ ) between lack of public transit being a barrier to those visiting who like the outdoors and also from Table $11(p=0.001)$ between those that like the outdoors and a general lack of interest with RUNP. All other barriers showed no significance above $90 \%$ and so have not been shown.

Table 7. Chi-squared of likelihood of visiting against liking the outdoors.

\begin{tabular}{lccc}
\hline & & \multicolumn{2}{c}{ Are You Likely to Visit in the Next 12 Months? } \\
\cline { 3 - 4 } & & Not Likely & Likely \\
\hline Do you like to be outdoors and & Yes & 93 & 80 \\
have fresh air? & No & 63 & 35 \\
\hline$(n=271)$ & Value & Df & Significance \\
Pearson Chi-Square & 2.839 & 1 & 0.092 \\
\hline
\end{tabular}

Table 8. Chi-Squared of biggest barrier to visiting RUNP against liking the outdoors.

\begin{tabular}{ccccccc}
\hline & & \multicolumn{5}{c}{ What Is the Biggest Barrier You Perceive to Visiting RUNP? } \\
\cline { 3 - 7 } & & Too Far & $\begin{array}{c}\text { No Public } \\
\text { Transit }\end{array}$ & No Car & $\begin{array}{c}\text { No } \\
\text { Information }\end{array}$ & $\begin{array}{c}\text { Not } \\
\text { Interested }\end{array}$ \\
\hline $\begin{array}{c}\text { Do you like to be outdoors } \\
\text { and have fresh air? }\end{array}$ & Yes & 76 & 24 & 11 & 17 & 31 \\
\hline$(n=271)$ & No & 32 & 9 & 3 & 11 & 35 \\
Pearson Chi-Square & Value & Df & Significance & & \\
\hline & 12.696 & 5 & 0.026 & \\
\end{tabular}

Table 9. Chi-square of RUNP being considered too far by OUTDOOR group.

\begin{tabular}{cccc}
\hline & & \multicolumn{2}{c}{ Is It Too Far? } \\
\cline { 3 - 4 } & & Yes & No \\
\hline Do you like to be outdoors and have & Yes & 113 & 60 \\
fresh air? & No & 51 & 47 \\
\hline$(n=271)$ & Value & Df & Significance \\
Pearson Chi-Square & 4.616 & 1 & $0.032^{* *}$ \\
\hline & $* * p<0.05$. &
\end{tabular}


Table 10. Chi-square of RUNP being considered not easily accessible by OUTDOOR group.

\begin{tabular}{cccc}
\hline & & \multicolumn{2}{c}{ Easily Accessible by Public Transit? } \\
\cline { 3 - 4 } & & Yes & No \\
\hline Do you like to be outdoors & Yes & 46 & 127 \\
and have fresh air? & No & 12 & 86 \\
\hline$(n=271)$ & Value & Df & Significance \\
Pearson Chi-Square & 7.653 & 1 & $0.006^{* *}$ \\
\hline \multicolumn{2}{c}{${ }^{* *} p<0.01}$.
\end{tabular}

Table 11. Chi-square of a lack of interest in RUNP by OUTDOOR group.

\begin{tabular}{cccc}
\hline & & \multicolumn{2}{c}{ Are You Interested in Visiting RUNP? } \\
\cline { 3 - 4 } & & Yes & No \\
\hline Do you like to be outdoors & Yes & 48 & 125 \\
and have fresh air? & No & 46 & 52 \\
\hline$(n=271)$ & Value & Df & Significance \\
Pearson Chi-Square & 10.173 & 1 & $0.001^{* *}$ \\
\hline \multicolumn{2}{c}{${ }^{* *} p<0.00}$.
\end{tabular}

The same three barriers of being too far, lack of public transit and a lack of interest were looked at for the group of respondents who answered they enjoy "appreciating nature, animals and scenery" (referred to as NATURE) as a motivation to visit UPs. As seen from Table 12, distance to the park was the greatest perceived barrier, with "lack of public transit" and "not interested" being second and third greatest similarly to the OUTDOUR motivational group. In this case, a greater significance is seen between the lack of public transit as a barrier to visiting, than distance from the park. For this group of potential consumers, a lack of public transit can be considered a bigger barrier than distance to the park as it showed a relationship at a higher confidence level of 99\% $(p=0.001)$ compared with $85 \%$ $(p=0.158)$ for distance to the park (see Tables 13 and 14). As witnessed previously with OUTDOOR consumers, the greatest significance was found for a general lack of interest in the RUNP $(p=0.000)$ (Table 15).

Table 12. Chi-square of biggest barrier to visiting RUNP against liking the nature.

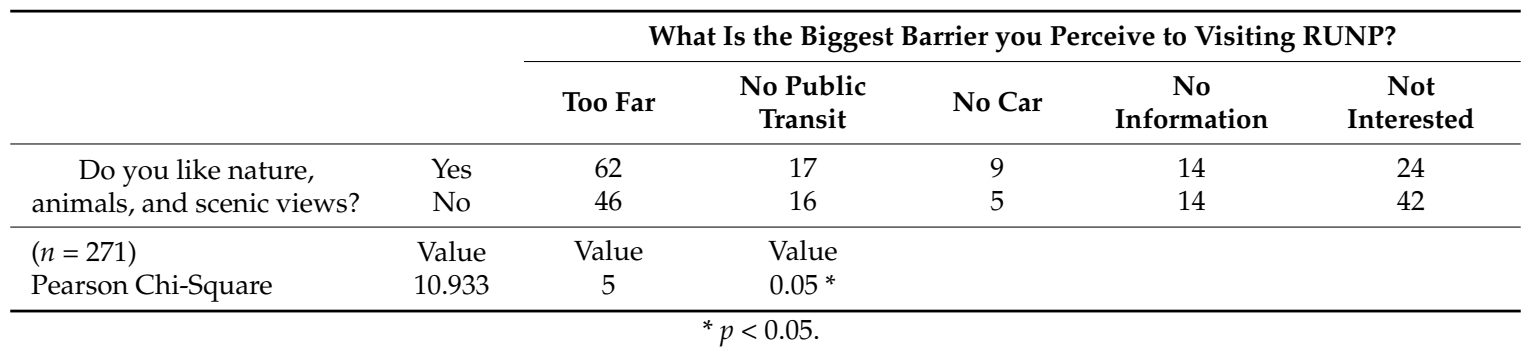

Table 13. Chi-square of RUNP being considered too far by NATURE group.

\begin{tabular}{cccc}
\hline & & \multicolumn{2}{c}{ Is It Too Far? } \\
\cline { 3 - 4 } & & Yes & No \\
\hline Do you appreciate nature, & Yes & 91 & 50 \\
animals and scenic areas? & No & 73 & 57 \\
\hline$(n=271)$ & Value & Df & Significance \\
Pearson Chi-Square & 1.990 & 1 & 0.158 \\
\hline
\end{tabular}


Table 14. Chi-square of RUNP not being easily accessible by public transit by NATURE group.

\begin{tabular}{cccc}
\hline & & \multicolumn{2}{c}{ Easily Accessible by Public Transit? } \\
\cline { 3 - 4 } & & Yes & No \\
\hline Do you appreciate nature, & Yes & 41 & 100 \\
animals and scenic areas? & No & 17 & 113 \\
\hline$(n=271)$ & Value & Df & Significance \\
Pearson Chi-Square & 10.295 & 1 & $0.001^{* *}$ \\
\hline & ${ }^{* *} p<0.1$. &
\end{tabular}

Table 15. Chi-square of a lack of interest in RUNP by NATURE group.

\begin{tabular}{cccc}
\hline & & \multicolumn{2}{c}{ Are You Interested in Visiting RUNP? } \\
\cline { 3 - 4 } & & Yes & No \\
\hline Do you appreciate nature, & Yes & 36 & 106 \\
animals and scenic areas? & No & 59 & 71 \\
\hline$(n=271)$ & Value & Df & Significance \\
Pearson Chi-Square & 12.623 & 1 & $0.000 * *$ \\
\hline & \multicolumn{2}{c}{$*<0.1}$. &
\end{tabular}

For both motivational groups, OUTDOOR and NATURE, the greatest significance and therefore implied biggest barrier to visiting is "a lack of interest" in the park. In regards to distance and perceiving the park as too far to travel to, both motivational groups showed a relationship between these variables at a confidence level greater than 95\%, apart from NATURE and their perception of distance to the park, which is can be considered ingsignificant with a confidence level around $85 \%$ $(p=0.158)$.

\section{Discussion}

Between the two motivational groups of OUTDOOR and NATURE, three barriers to visiting were investigated (lack of interest, distance, and lack of public transit) and all but one (distance) showed a significant relationship between the variables in question at either $90 \%$ or $95 \%$ confidence levels. Distance to the park showed no significant relationship with visiting for the NATURE motivational group. This implies that despite having an interest in urban parks and having a relevant background and motivation for visiting RUNP, distance to the park, a lack of public transit, and a general lack of interest in the park are all contributing factors in stopping these millennials from visiting.

As can be seen from the results shown, for the motivational group OUTDOOR, both hypotheses are supported. Both showed a significant relationship between motivations to visit and distance and that it was the largest barrier. However, for motivational group NATURE, only hypothesis 1 can be taken as true as distance was shown to be the largest barrier at a 95\% confidence level, but it was shown to be not significant on its own in discouraging the NATURE group from visiting. For this group, "lack of public transit" was significant, as was "lack of interest."

With this being said, the previously stated hypothesis that distance to the park being the largest barrier cannot then be completely discounted or accepted. The largest barrier with the lowest significance value was "a general lack of interest" in RUNP (at a 99\% confidence level) and should therefore be considered the greatest barrier to RUNP. It can also be said that barriers to millennial visitors can be considered more complex with different motivational groups perceiving various barriers more strongly than others. In this way, future studies should perhaps consider splitting millennials into different groups to be analyzed instead of simply by age.

One prominent finding from previous studies showed millennials travelling farther distances to visit urban parks [8]. Within this study, however, both the NATURE and OUTDOOR respondent groups cite distance as a large barrier to visiting just not the largest. It could then be considered that 
these findings refute previous findings [8]. All respondents were interviewed within the "urban" catchment of RUNP and yet $75 \%$ had never heard of the urban park and $90 \%$ had never visited. After hearing more information about the park and where it was located, $57 \%$ of respondents were still unlikely to travel there with only $9 \%$ saying it was likely they would.

Both NATURE and OUTDOOR groups showed a significant (95\% confidence level) relationship between "lack of public transit" as a barrier to visiting, implying that this is a major issue to millennial travellers. The accessibility of RUNP and other urban parks to city dwellers is unique and it is this "niche" that draws potential visitors. With many millennials not owning a car, public transit is their main source of transportation and 13\% say that transit is lacking to RUNP. It is encouraging that $74 \%$ would use a shuttle bus service if it were offered and would consider paying the same amount as a current transit pass.

A further point to consider is that with the advancement in technology, there is more information available for this generation in an instant than ever before. Millennials are becoming more used to having information quickly and easily accessible and that there is an obstacle of time in getting them to experience the outdoors [20]. This observation can be applied to this research in that poor accessibility and distance to RUNP not only creates a barrier of physical difficulty in visiting the park but it also creates a barrier of time in which to get there. With the greatest barrier to travellers being a "lack of interest" in RUNP, it can be considered that perhaps lack of information and access to information is truly the largest issue for RUNP in getting millennials to visit. Parks are no exception to online brand management [36]. For example, in 2016, Yellowstone National Park collected nearly 700 thousand likes on its Facebook page and Parks Canada acquired nearly 121 thousand followers on Twitter. These numbers indicate that social media can be a very powerful tool to reach a desired audience like millennials who are extremely reliant on technology [3]. Rouge Park's online presence could be greatly improved. Of those not likely to visit in the next year, $8 \%$ showed that lack of information was their main barrier to visiting along with $31 \%$ saying a general lack of interest is their main barrier. A well-developed website could help the park rank higher on search engines and have a positive effect on the park's awareness among Toronto's millennial residents. In addition to website improvements, RUNP could also be active on social media channels to help create engagement and spread awareness of the park through the e-word of mouth. As previously mentioned, one study applied the theory of distance decay to American national park visitors and implied that the greater attributes a park had, the farther consumers were willing to travel [24]. If this is true, RUNP should consider a greater awareness of their park and what activities are offered as perhaps their key to greater visitor traffic. A strong online presence is key with this demographic. Millennials are known as being extremely skilled with technology [18] and use it to research potential trips. With the lack of awareness of RUNP that is seen, perhaps having a stronger online presence will help in marketing to this population.

\section{Conclusions}

Rouge National Urban Park is now Canada's first urban national park. With increased urbanization, protected urban green space is important to help with conservation efforts and community health and well-being. There is, however, low awareness of the park in potential consumers. Millennials make up almost half of the population of Toronto and are a key demographic of potential urban park users. This study has shown that there is a lack of awareness amongst this group of RUNP, with poor online branding and marketing being cited as a key problem area. Millennials are defined broadly as being tech-savvy and using technology when making travel plans and ideas. A poor online presence can be considered damaging when trying to target this consumer market. Marketing to this demographic within such a medium may be a way to overcome barriers and attract this key visitor segment who in turn may help increase environmental protection. A recommendation is to invest more resources into redesigning certain marketing practices as well as obtaining a greater understanding of this priority market to increase overall visitation. Awareness could be raised through three mediums that match millennials' key interests. First, improve RUNP's online presence. Second, promote the park 
at festivals and events and third, partner with tourist or cultural attractions for marketing. For instance, the park's website is static and not mobile friendly. A well-developed website could help the park rank higher on search engines and have a positive effect on awareness among GTA residents. In addition to website improvements, RUNP should also be active on social media channels including Facebook and Instagram. These two social media channels would help to create engagement and spread awareness of the park through the e-word of mouth, an important marketing tool amongst the technology driven millennial generation. Attracting millenials, especially ethnic groups in this segment, is vital, as the city is becoming increasingly diverse, and this generation will then communicate their outdoor preferences in the future to the next generation.

Many millennials use public transport to access the city and travel around, with fewer people in the city center owning a car than those further out. Those that live centrally cannot access the urban park easily due to poor public transport links and those that choose to live further from the central city core have a higher propensity to own a car, but now RUNP is perceived as being too far to travel too, thereby losing the "urban" niche. This then contradicts the idea that millennials are willing to travel farther to visit urban parks. This barrier can be overcome by considering transport links to urban parks and accessibility options for millennials that have moved further out of the city core. Despite the fact that the majority of respondents think that the biggest barrier to visit RUNP is distance, the survey results indicate that almost three quarters of respondents would use a shuttle bus service if it was offered. The year 2017 was declared as Canada's 150th birthday. To celebrate, Parks Canada gave away free park passes to all national parks and has also established a shuttle bus service in partnership with Parkbus (www.parkbus.ca) from the downtown Toronto core. Perhaps these efforts will entice millennials to visit.

\section{Limitations and Future Research}

The scope of the study could be widened geographically to include the Greater Toronto Area (GTA) to investigate whether any similar trends are seen as more consumers outside of the city core have a car and therefore easier accessibility to RUNP but then have a greater distance to travel. Not having access to a vehicle was not considered the largest barrier to visiting RUNP, but $23 \%$ of respondents considered it an issue. The farther you travel from the center of Toronto, the more people use their cars, and the more people who have cars [22]. Perhaps surveying millennials further from the city may show a different result to that seen here. Those who live in the core of the city moved there for accessibility and easier access to amenities leading to the logical conclusion that fewer people then need to use and want to use a car as their main source of transport. Age is also a factor, with millennials being 2.5 times less likely to use a car than their older counterparts [22]. In terms of future considerations, a combination distance decay study into whether age and park attributes affect distances visitors would travel to RUNP could be done. This would determine if millennials are willing to travel greater distances than older consumers, and if, once better branding is in place, greater attributes will in fact attract more visits.

Author Contributions: Daniela Furtado, Yana Mykhayletska, Mana Majedian, and Anna Kirichenko conducted the surveys used in this research study. They collected all data and they contributed initial research into Rouge Park. Gillian Ramsay formed the hypotheses of the study, conducted statistical analysis on the data and wrote the manuscript. Rachel Dodds provided guidance and support to all the researchers throughout this project, as well as providing the initial scope, ideas and direction for the study. She also provided edits and writing feedback.

Conflicts of Interest: The authors declare no conflict of interest.

\section{References}

1. Shultis, J.; More, T. American and Canadian National Park Agency responses to declining visitation. J. Leis. Res. 2011, 43, 110-132. 
2. Parks Canada. Parks Canada's Departmental Performance Report; 2013-2014; Parks Canada Agency: Gatineau, QC, Canada, 2014.

3. Morath, S.J. A park for everyone: The national park service in urban America. Nat. Resour. J. 2016, 56, 1-22. [CrossRef]

4. $\quad$ Evert, K.; Ballard, E.B.; Elsworth, D.J.; Oquiñena, I.; Schmerber, J.; Stripe, R.E. National Park. In Encyclopedic Dictionary of Landscape and Urban Planning; Springer: Berlin/Heidelberg, Germany, 2010; pp. 600-601.

5. Parks Canada. Parks Canada Attendance: 2010-2011 to 2014-2015; Parks Canada Agency: Gatineau, QC, Canada, 2015.

6. $\quad$ Evert, K.; Ballard, E.B.; Elsworth, D.J.; Oquiñena, I.; Schmerber, J.; Stripe, R.E. Urban Park. In Encyclopedic Dictionary of Landscape and Urban Planning; Springer: Berlin/Heidelberg, Germany, 2010; pp. 1081-1082.

7. Foresta, R. America's urban national parks. In Urbanism Past and Present; University of Wisconsin-Milwaukee: Milwaukee, WI, USA, 1984; Volume 18, pp. 1-14.

8. Rossi, S.; Byrne, J.; Pickering, C. The role of distance in peri-urban national park use: Who visits them and how far do they travel? Appl. Geogr. 2016, 63, 77-88. [CrossRef]

9. National Park Service. Frequently Asked Questions. Available online: https://www.nps.gov/lowe/faqs.htm (accessed on 27 September 2016).

10. De Vries, S.; Verheji, R.A.; Groenewegen, P.P.; Spreeuwenberg, P. Natural environments-healthy environments? An exploratory analysis of the relationship between greenspace and health. Environ. Plan. 2003, 35, 1717-1731. [CrossRef]

11. Byrne, J.; Wolch, J.; Zhang, J. Planning for environmental justice in an urban national park. J. Environ. Plan. Manag. 2009, 52, 365-392. [CrossRef]

12. Harvey, D. Fertile Ground for New Thinking: Improving Toronto's Parks; Metcalf Foundation: Toronto, ON, Canada, 2010; pp. 1-51.

13. Dudley, N.; Higgins-Zogib, L.; Hockings, M.; MacKinnon, K.; Sandwith, T.; Stolton, S. National parks with benefits: How protecting the planet's biodiversity also provides ecosystem services. Solutions 2011, 2, 87-95.

14. O'Dell, P. Redefining the national park service role in urban areas. J. Leis. Res. 2016, 48, 5-11.

15. Skena, R. Region's National Parks Benefit Economy; Pittsburgh Tribune-Review, 2012. Available online: http://triblive.com/x/pittsburghtrib/news/regional/s_784262.html (accessed on 1 March 2016).

16. Lin, B.B.; Fuller, R.A.; Bush, R.; Gaston, K.J.; Shanahan, D.F. Opportunity or orientation? Who uses urban parks and why. PLoS ONE 2014, 9, e87422. [CrossRef] [PubMed]

17. Canadian Tourism Commission. Canada Millennial Domestic Travel Summary Report; CTC Research: Vancouver, BC, Canada, 2015. Available online: https://www.destinationcanada.com/sites/default/files/2016-11/ Programs_MillennialTravel_DomesticReport_EN.pdf (accessed on 24 May 2017).

18. Coletto, D. R U Ready 4 Us? - An Introduction to Canadian Millennials; Canadian Millennials: Ottawa, ON, Canada, 2012.

19. City of Toronto. City of Toronto Community Council Profiles, Area C-Toronto \& East York. Available online: http:/ /www1.toronto.ca/City\%20Of\%20Toronto/City\%20Planning/Wards/Files/pdf/C/CCA_ STE\%20Census\%20Profile\%202011.pdf (accessed on 25 May 2017).

20. Barton, K.S. Colorado's millennial generation: youth perceptions and experiences of nature. J. Geogr. 2012, 111, 213-223. [CrossRef]

21. Angus Reid Institute. GTA Woes: Transit Top Concern for Residents; Housing Costs Threaten to Push Millennials Out. Available online: http://angusreid.org/toronto-housing-and-transit/ (accessed on 28 November 2016).

22. Turcotte, M. Dependence on cars in urban neighbourhoods. Can. Soc. Trends 2008, 85, 20-30.

23. Taylor, P.J.; Openshaw, S. Distance Decay in Spatial Interactions. In Concepts and Techniques in Modern Geography; Geo Abstracts Ltd.: Norwich, UK, 1975.

24. Hanink, D.M.; White, K. Distance effects in the demand for wildland recreations services: The case of national parks in the United States. Environ. Plan. A 1999, 31, 477-492. [CrossRef]

25. Zhang, X.; Wall, G.; Du, J.K.; Gan, M.Y.; Nie, X. The travel patterns and travel distance of tourists to national parks in China. Asia Pac. J. Tour. Res. 1999, 4, 27-34. [CrossRef]

26. Rung, A.L.; Mowen, A.J.; Broyles, S.T.; Gustat, J. The role of park conditions and features on park visitation and physical activity. J. Phys. Act. Health 2011, 8, 178-187. [CrossRef] 
27. Rouge Park. Rouge Park Map. Available online: http://www.rougepark.com/explore/park_map.php (accessed on 9 February 2016).

28. Wallace, A.W. Harper Announces Expansion of Rouge National Urban Park; Toronto Star: Toronto, ON, Canada, 2015.

29. David Suzuki Foundation. Establishing Rouge National Park. Available online: http://www.davidsuzuki. org/issues/wildlife-habitat/projects/rouge-national-park/establishing-rouge-national-park/ (accessed on 24 January 2016).

30. Parks Canada. Parks Canada-Rouge National Urban Park Initiative. Available online: https://www.pc. gc.ca/en/pn-np/on/rouge/info/ /media/5DD00D091FB54DEEA1B9178E33BD5FB9.ashx (accessed on 24 January 2016).

31. Rouge Park. Physical Landscapes. Available online: http://www.rougepark.com/unique/landscapes.php (accessed on 24 January 2016).

32. Rouge Park. Biodiversity. Available online: http://www.rougepark.com/unique/ecology/biodiversity.php (accessed on 24 January 2016).

33. Rouge Park. Cultural heritage. Available online: http://www.rougepark.com/unique/cultural.php (accessed on 24 January 2016).

34. Rouge Park. About Us. Available online: http://www.rougepark.com/about/index_about.php (accessed on 24 January 2016).

35. John, W.S.; Johnson, P. The pros and cons of data analysis software for qualitative research. J. Nurs. Scholarsh. 2000, 32, 393-397. [CrossRef]

36. Skift. Public Parks in U.S. Cities Find New Ways to Market to Locals and Tourists. Available online: http:/ /skift.com/2014/09/05/public-parks-in-u-s-cities-find-new-ways-to-market-to-locals-andtourists / (accessed on 7 February 2016).

(C) 2017 by the authors. Licensee MDPI, Basel, Switzerland. This article is an open access article distributed under the terms and conditions of the Creative Commons Attribution (CC BY) license (http:/ / creativecommons.org/licenses/by/4.0/). 